\title{
Morphologic Evaluation of Ductus Diverticulum Using Multi - Detector Computed Tomography: Comparison with Traumatic Pseudoaneurysm of the Aortic Isthmus
}

\author{
Jun Hyung Ann, ${ }^{1}$ Eun Young Kim, ${ }^{1,}$ Yu Mi Jeong, ${ }^{1}$ Jeong Ho Kim, ${ }^{1}$ Hyung Sik Kim, ${ }^{1}$ and Hye-Young Choi ${ }^{1}$ \\ ${ }^{1}$ Department of Radiology, Gachon University Gil Medical Center, Incheon, Republic of Korea \\ "Corresponding author: Eun Young Kim, Department of Radiology, Gachon University Gil Medical Center, Incheon, Republic of Korea. Tel: +82-324603060, Fax: +82-324603065, \\ E-mail: oneshot0229@gmail.com
}

Received 2016 March 23; Revised 2016 May 10; Accepted 2016 May 19.

\begin{abstract}
Objectives: To evaluate morphologic variations at the aortic isthmus with particular attention to ductus diverticulum, a mimicker of traumatic pseudoaneurysm, and to describe differences using Computed Tomography (CT) images.

Patients and Methods: From December 2013 to December 2014, patients who underwent a chest CT examination after blunt trauma at our emergency department were included. Aortic isthmus morphologies were evaluated using multiplanar reconstruction (MPR) and maximum intensity projection (MIP) images as follows. Type I -concave contour, type II -convexity without a discrete bulge, or type III -a discrete focal bulge (defined as ductus diverticulum).

Results: After excluding 11 cases of traumatic pseudoaneurysm of the aortic isthmus, a total of 432 trauma patients (mean age $=47.1 \pm 19.1$ years, number of males $=318$ ) were evaluated for aortic isthmus morphology, and classified as follows; type I $(n=240,55.6 \%)$, type II $(n=157,36.3 \%)$, and type III $(n=35,8.1 \%)$. As compared with traumatic pseudoaneurysm $(n=11)$, ductus diverticulum had a smaller vertical diameter $(5.5 \pm 1.3 \mathrm{~mm}$ vs. 11.2 $\pm 2.7 \mathrm{~mm}, \mathrm{P}<0.001)$, a broader base $(14.9 \pm 4.1 \mathrm{~mm}$ vs. $8.8 \pm 4.5 \mathrm{~mm}, \mathrm{P}<0.001)$, a smoother margin $(97.1 \%$ vs. $27.3 \%, \mathrm{P}<0.001)$, and formed obtuse angle with the aortic wall. Furthermore, ductus diverticulum was not associated with the presence of a dissection flap or hemomediastinum. Conclusion: Ductus diverticulum, a mimicker of traumatic pseudoaneurysm of the aortic isthmus, is a frequently observed anatomic variant during CT examinations. Familiarity with its CT imaging findings could avoid it being confused with traumatic pseudoaneurysm in blunt trauma patients.
\end{abstract}

Keywords: Ductus Diverticulum, Aorta, Thoracic, Tomography, X-ray Computed, Trauma

\section{Background}

The aortic isthmus, the proximal descending thoracic aorta immediately distal to the subclavian artery, typically exhibits slight constriction at the attachment point of ductus arteriosus (1). A focal bulge on the inner curvature of the isthmus (referred to as aortic diverticulum) is known to be a normal variant, and is believed to be derived from the infundibula portion of ductus arteriosus embryologically. A previous angiographic study reported a 9.7\% prevalence of aortic diverticulum among 103 adult patients with blunt trauma (2).

Aortic isthmus is also prone to acute aortic injury because tethering of the aorta by the ligamentum arteriosum makes it sensitive to shearing forces during sudden deceleration (3). On the other hand, partial aortic disruption is a result of focal disruption of the intima and media (usually with preservation of the adventitia), resulting in a focal pseudoaneurysm. Since the aortic isthmus is the most vulnerable aortic site to traumatic injury, an understanding of the morphologic variations of the aortic isthmus, includ- ing ductus diverticulum could help avoid misdiagnoses of traumatic aortic injuries after blunt trauma. Although multi-detector row computed tomography (MDCT) has become the imaging modality of choice for the assessment of thoracic injuries after blunt trauma because of its noninvasiveness and good accessibility (4), no information is available on the detailed morphology of aortic isthmus as determined by MDCT.

\section{Objectives}

Accordingly, the purposes of this study were to evaluate morphologic variations at the aortic isthmus with focus on ductus diverticulum and to identify the characteristic features of ductus diverticulum on Computed Tomography (CT) images. 


\section{Patients and Methods}

\subsection{Patients and Examinations}

Five hundred forty-six patients underwent chest CT examinations for the evaluation of thoracic injuries after trauma at our emergency department from December 2013 to December 2014. After excluding 103 patients who underwent non-contrast CT and 11 patients with radiologically and clinically confirmed traumatic pseudoaneurysm of the aortic isthmus, the chest CT scans of 432 patients were finally included in this study. Patients were subcategorized by age as pediatrics ( $\leq 18$ years) or adults $(>18$ years).

The parameters of the chest CT examinations, which were performed using a Somatom definition edge 128 scanner (Siemens Medical Solutions, Forchheim, Germany) were as follows; $80-120 \mathrm{kVp}, 170 \mathrm{mAs}, 10 \mathrm{~mm} / \mathrm{s}$ table feed, 1-s rotation time, 3.0 - $5.0 \mathrm{~mm}$ slice thickness, and a 5.0 $\mathrm{mm}$ interval. Synthetic sagittal and coronal images were reformatted at intervals of 3-mm and fully covered the region from the anterior skin to the back of the chest. The post-enhancement images were obtained within $30-40$ seconds after the start of an injection of $120 \mathrm{~mL}$ nonionic iodinated contrast material (Ultravist $300 \mathrm{mg} / \mathrm{mL}$, Schering AG, Berlin, Germany) administered through the antecubital vein at a rate of 3-4 mL/s.

The institutional review board at our hospital approved this retrospective study and waived the requirement for informed patient consent.

\subsection{Image Analysis}

All CT images were reviewed on a picture archiving and communication system (PACS; PiView; infinitt healthcare, Seoul, Korea) workstation using the mediastinal window setting (window width 440 hounsfield units (HU) and window level $45 \mathrm{HU}$ ). A subspecialty-trained chest radiologist and a fourth-year radiology resident retrospectively reviewed MDCT images by consensus. Using multiplanar reconstruction images of the thoracic aorta, morphologic types of aortic isthmus were evaluated and categorized as previously described (5) as follows. Type I (concave contour of the aortic isthmus with parallel walls and uniform diameter), type II (mild straightening or convexity of the aortic isthmus without a discrete bulge), and type III (defined as ductus diverticulum) a discrete focal bulge of the aortic isthmus (Figure 1). In addition, detailed morphologic evaluations of ductus diverticulum were made using multiplanar reconstruction images and maximum intensity projection (MIP) images to evaluate sizes of focal bulging (base and vertical diameters of the protrusion), margins (smooth or irregular), and angles (obtuse or acute) of focal bulge with the aortic wall. The presence of a dissection flap and hemomediastinum were also evaluated. These findings were compared with those of the CT images of traumatic pseudoaneurysm of aortic isthmus $(n=11)$ also obtained during the study period.

\subsection{Statistical Analysis}

Descriptive statistics are reported as proportions or means \pm standard deviations (SDs). Patients allocated to age groups (pediatric and adult) in the analysis of ductus diverticulum frequency and size. Pearson's chi-squared test or Fisher's exact test for categorical variables was used to compare subjects with or without ductus diverticulum. Continuous variables were compared using the Student's ttest. Statistical significance was calculated at the 95\% confidence level $(\mathrm{P}<0.05)$. Commercially available software was used for data processing and analysis (PASW, version 17.0; SPSS, Chicago, IL, USA).

\section{Results}

The baseline characteristics of the study population are summarized in Table 1 . For all 432 trauma patients, the mean age was $47.1 \pm 19.1$ years and 318 were male (73.6\%). Morphologic types of aortic isthmus and their prevalence were as follows; type I $(n=240,55.6 \%)$, type II ( $n=157,36.3 \%$ ), and type III $(\mathrm{n}=35,8.1 \%)$. The prevalence of ductus diverticulum was non-significantly lower in pediatrics than in adult cases ( $n=1 / 39,2.9 \%$ vs. $n=34 / 393,8.7 \%$, respectively) $(\mathrm{P}=0.184)$.

As compared with traumatic pseudoaneurysm of the aortic isthmus ( $\mathrm{n}=11$, mean age $=40.8 \pm 7.4$ years, number of male $=9$ ), ductus diverticulum had a smaller median vertical diameter $(5.5 \pm 1.3 \mathrm{~mm}$ vs. $11.2 \pm 2.7 \mathrm{~mm})$ $(\mathrm{P}<0.001)$ and a broader base $(14.9 \pm 4.1 \mathrm{~mm}$ vs. $8.8 \pm$ $4.5 \mathrm{~mm})(\mathrm{P}<0.001)$ (Table 2$)$. Notably, ductus diverticulum more frequently had a smooth margin than traumatic pseudoaneurysm (97.1\% vs. 27.3\%) $(\mathrm{P}<0.001)$. In all cases, ductus diverticulum exhibited an obtuse angle with the aortic wall; whereas, traumatic pseudoaneurysm formed acute angles between the cranial end (72.7\%) and the caudal end $(81.8 \%)$ of the focal bulge and the aortic wall. Furthermore, all traumatic pseudoaneurysm had a dissection flap in the aorta and $72.7 \%$ exhibited hemomediastinum (Figure 2); whereas, ductus diverticulum was not associated with a dissection flap or hemomediastinum in any patient.

\section{Discussion}

Embryologically, the aorta is narrowed between the left subclavian artery and ductus arteriosus in newborns. However, this narrowing usually disappears at two months 

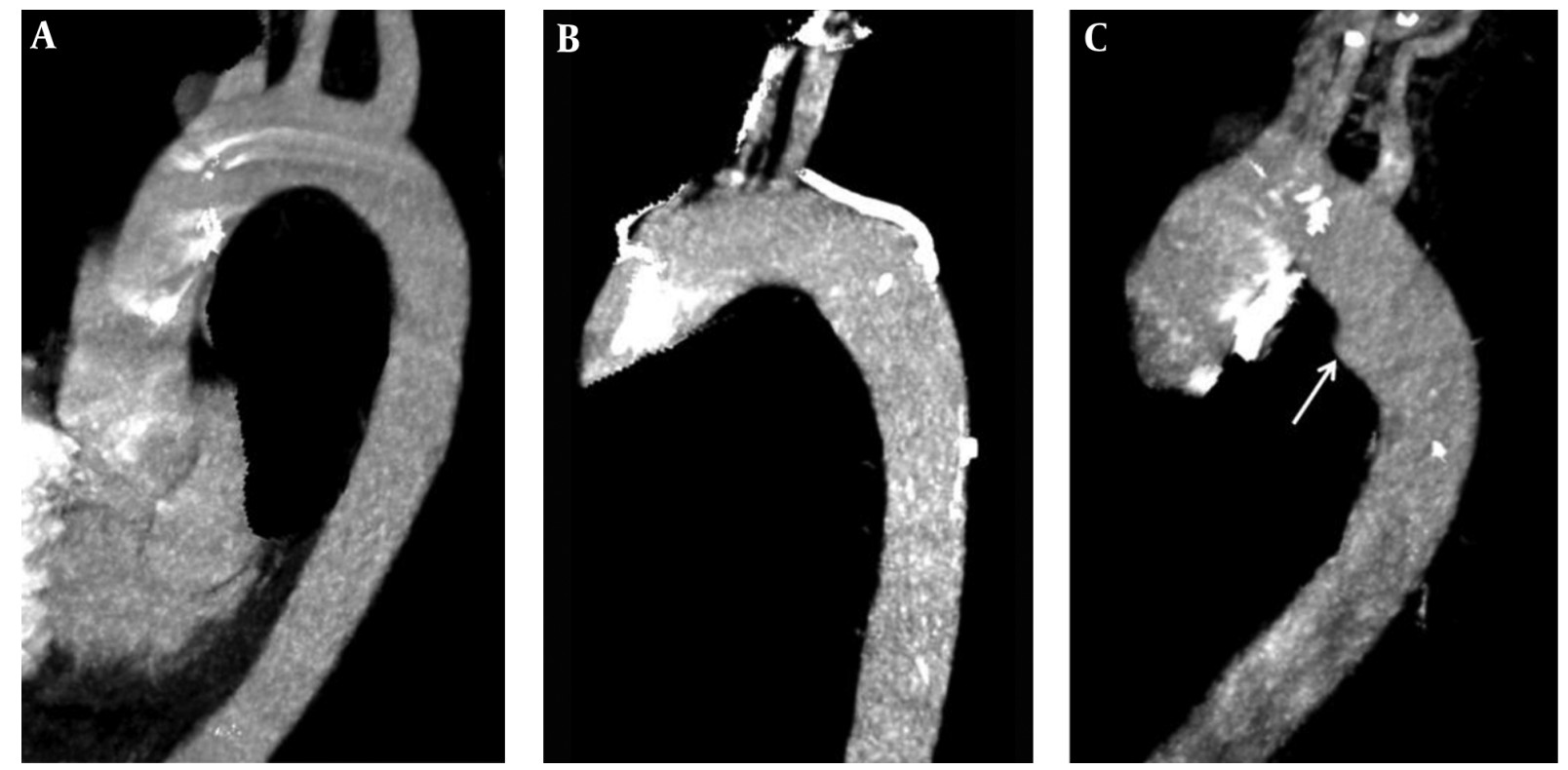

Figure 1. Maximal intensity projection images of three morphologic variants of aortic isthmus; A, Type I, concave contour with parallel walls and uniform diameter; B, Type II, diffuse mild convexity of the aortic isthmus; C, Type III, aortic isthmus demonstrating focal bulge (arrow), which is referred to as ductus diverticulum; Ductus diverticulum has a smooth margin and a broad base and meets the aortic wall at an obtuse angle.

Table 1. Characteristics of Trauma Patients by Type of Aortic Isthmus Morphology ${ }^{\mathrm{a}}$

\begin{tabular}{|c|c|c|c|c|c|}
\hline Characteristics & All $(n=432)$ & Type I $(n=240)$ & Type II (n=157) & Type III $(n=35)$ & P Value \\
\hline Age, years & $47.1 \pm 19.1$ & $47.6 \pm 19.6$ & $45.2 \pm 18.9$ & $52.4 \pm 15.6$ & $0.161^{b}$ \\
\hline Pediatrics $(\leq \mathbf{1 8} \mathbf{y})$ & $39(9.0)$ & $23(9.6)$ & $15(9.6)$ & $1(2.9)$ & $0.414^{c}$ \\
\hline Adults (> 18 y) & $393(91.0)$ & $217(90.4)$ & $142(90.4)$ & $34(97.1)$ & \\
\hline Male & $318(73.6)$ & $183(76.3)$ & $113(72.0)$ & $22(62.9)$ & $0.206^{c}$ \\
\hline Blunt Trauma & & & & & $0.019^{c}$ \\
\hline Motor vehicle accidents & $241(55.8)$ & $138(57.5)$ & $89(56.7)$ & $14(40.0)$ & \\
\hline Pedestrians struck by vehicles & $126(29.2)$ & $63(26.3)$ & $52(33.1)$ & $11(31.4)$ & \\
\hline Acts of violence & $24(5.6)$ & $14(5.8)$ & $9(5.7)$ & $1(2.9)$ & \\
\hline Falls & $28(6.5)$ & $18(7.5)$ & $4(2.5)$ & $6(17.1)$ & \\
\hline Others & $13(3.0)$ & $7(2.9)$ & $3(1.9)$ & $3(8.6)$ & \\
\hline
\end{tabular}

${ }^{a}$ Values are means \pm standard deviations or No. (\%)

${ }^{\mathrm{b}}$ Kruskal-Wallis test

${ }^{\mathrm{c}}$ Chi-squared test

of age since the blood flow through the ductus arteriosus stops and the flow is increased through the narrowed region (1). However, mild narrowing and a circumferential bulge below the isthmus (also referred to as aortic isthmus and aortic spindle) are considered normal variants that could persist anatomically (6). Ductus diverticulum (a focal bulge of the aortic isthmus) has been reported to have a prevalence of $9.7 \%$ based on thoracic aortography findings, and can mimic traumatic pseudoaneurysm (5). In the present study, we evaluated morphologic variants of the aortic isthmus using MDCT images. The most common morphology found was type I (55.6\%), which was followed by types II (mild straightening or convexity of the aortic isthmus without a discrete bulge; $36.3 \%$ ) and III (ductus diverticulum; 8.1\%). Although the prevalence of ductus diverticulum was slightly lower in pediatrics than in 
Table 2. Morphologic Characteristics of Ductus Diverticulum and Traumatic Pseudoaneurysm ${ }^{\mathrm{a}}$

\begin{tabular}{|c|c|c|c|}
\hline Characteristics & Ductus Diverticulum $(\mathbf{n}=35)$ & Traumatic Pseudoaneurysm ( $\mathbf{n}=11)$ & P Value \\
\hline \multicolumn{4}{|l|}{ Size of the focal bulging (mm) } \\
\hline Base & $14.9 \pm 4.1$ & $8.8 \pm 4.5$ & $<0.001^{\mathrm{b}}$ \\
\hline Vertical diameter & $5.5 \pm 1.3$ & $11.2 \pm 2.7$ & $<0.001^{\mathrm{b}}$ \\
\hline \multicolumn{4}{|l|}{ Margin } \\
\hline Smooth & $34(97.1)$ & $3(27.3)$ & $<0.001^{\mathrm{C}}$ \\
\hline Irregular & $1(2.9)$ & $8(72.7)$ & \\
\hline \multicolumn{4}{|c|}{ Angle between cranial end of the focal bulging and aortic wall } \\
\hline Acute & 0 & $8(72.7)$ & $<0.001^{\mathrm{C}}$ \\
\hline Obtuse & $35(100.0)$ & $3(27.3)$ & \\
\hline \multicolumn{4}{|c|}{ Angle between caudal end of the focal bulging and aortic wall } \\
\hline Acute & 0 & $9(81.8)$ & $<0.001^{\mathrm{c}}$ \\
\hline Obtuse & $35(100.0)$ & $2(18.2)$ & \\
\hline Presence of dissection flap & 0 & $11(100.0)$ & \\
\hline Presence of hemomediastinum & 0 & $87(72.7)$ & $<0.001^{\mathrm{c}}$ \\
\hline $\begin{array}{l}{ }^{\mathrm{a}} \text { Values are means } \pm \text { standard devi } \\
\text { b Student t- test } \\
{ }^{\mathrm{c}} \text { Fisher's exact test }\end{array}$ & & & \\
\hline
\end{tabular}
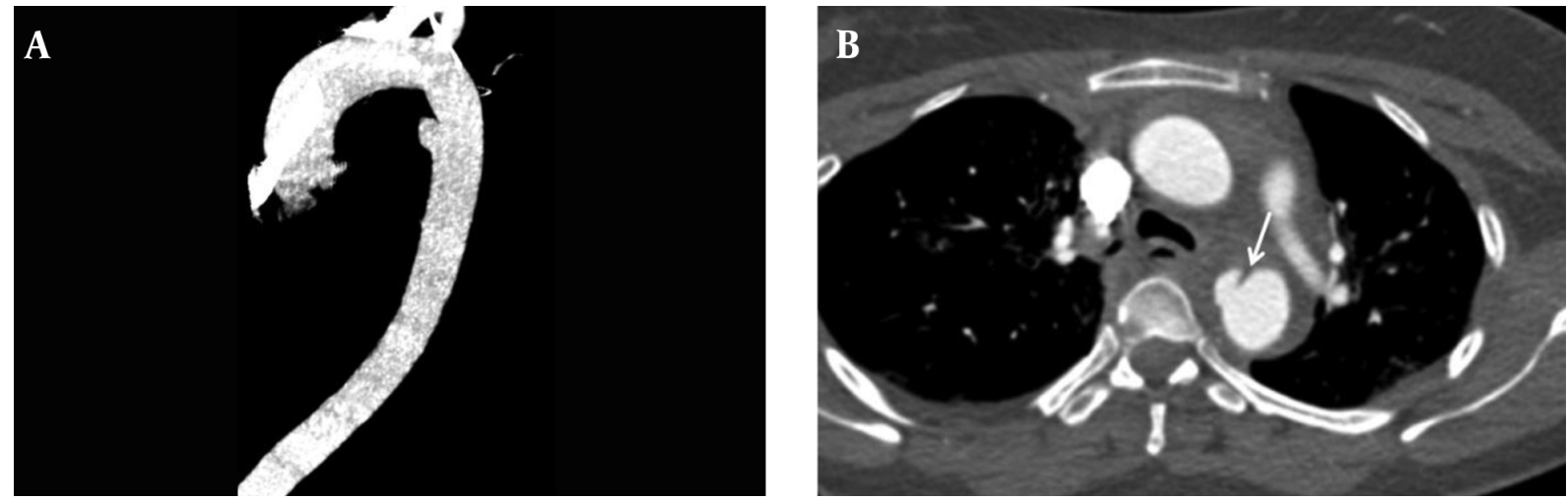

Figure 2. CT images of acute traumatic pseudoaneurysm of the aortic isthmus; A, Maximal intensity projection image of traumatic pseudoaneurysm of the aortic isthmus; The protrusion meets the aortic wall at an acute caudal angle; B, Axial image shows a dissection flap (arrow) and hemomediastinum.

adults, the difference was statistically insignificant. Since the number of pediatric patients was small, it needs further study to verify the relationship. Furthermore, there were no infants included in the present study, but they have previously been reported to exhibit a ductus diverticulum prevalence of up to $33 \%$ by thoracic angiography (1).

Recognition of the appearance of ductus diverticulum is important after blunt trauma because the isthmus is vulnerable to traumatic aortic injury. For this reason, we also sought to identify imaging features capable of differentiating ductus diverticulum and traumatic pseudoaneurysm of the aortic isthmus. In agreement with previous angiographic studies $(5,7)$, ductus diverticulum was found to have a smaller vertical height and a broader base than traumatic pseudoaneurysm on multiplanar CT images. Although it was reported in a conventional angiography study that atypical ductus diverticulum shows loss of the gentle superior angle of typical ductus diverticulum (7), in the present study, all ductus diverticula demonstrated an obtuse angle with the aortic wall. Furthermore, the absence of an intimal flap and hemomediastinum were found to be characteristic of ductus diverticulum but not 
of traumatic pseudoaneurysm on CT images.

Morphologic variations of the aortic isthmus sometimes prevent confident differentiation of ductus diverticulum and aortic injury blunt trauma. The absence of evidence regarding morphologic variations of the aortic isthmus and of the prevalence and imaging characteristics of ductus diverticulum as determined by CT encouraged us to undertake this study on patients who visited our emergency department for blunt trauma. MDCT is an excellent tool for morphologic evaluations because of its multiplanar reconstruction capability and excellent image resolution. Moreover, MIP images of vessels are similar to digital subtraction angiography images in that they allow any desired projection to be visualized from a single data acquisition set (8). MDCT allows the presence of intimal flap and mediastinal hematoma to be easily identified, and enables the evaluation of any injury of the lung, mediastinum, bone, or chest wall.

In conclusion, ductus diverticulum, a mimicker of traumatic pseudoaneurysm of the aortic isthmus, is a frequently observed anatomic variant on CT images. Familiarity with the image findings of ductus diverticulum could help avoid a misdiagnosis of traumatic aortic injury after blunt trauma.

\section{Footnotes}

Authors' Contributions: All authors participated in the concept/design, data interpretation, drafting, and critical revision of the article. The statistical analysis was conducted by Eun Young Kim.

Conflict of Interest: The authors have no potential conflict of interest to declare.

\section{References}

1. Abrams H. The normal thoracic aorta. In: Abrams H, editor. Angiography. 2 ed. Boston: Little: Brown \& Co;1971. p. 306.

2. Grollman JH. The aortic diverticulum: a remnant of the partially involuted dorsal aortic root. Cardiovasc Intervent Radiol. 1989;12(1):14-7. [PubMed: 2496921].

3. Benjamin MM, Roberts WC. Fatal aortic rupture from nonpenetrating chest trauma. Proc (Bayl Univ Med Cent). 2012;25(2):121-3. [PubMed: 22481840].

4. Steenburg SD, Ravenel JG. Multi-detector computed tomography findings of atypical blunt traumatic aortic injuries: a pictorial review. Emerg Radiol. 2007;14(3):143-50. doi: 10.1007/s10140-007-0620-2. [PubMed: 17564733].

5. Goodman PC, Jeffrey RB, Minagi H, Federle MP, Thomas AN. Angiographic evaluation of the ductus diverticulum. Cardiovasc Intervent $R a$ diol. 1982;5(1):1-4. [PubMed: 6805955].

6. Fisher RG, Sanchez-Torres M, Whigham CJ, Thomas JW. "Lumps" and "bumps" that mimic acute aortic and brachiocephalic vessel injury. $R a$ diographics. 1997;17(4):825-34. doi: 10.1148/radiographics.17.4.9225385. [PubMed: 9225385].

7. Morse SS, Glickman MG, Greenwood LH, Denny DJ, Strauss EB, Stavens $\mathrm{BR}$, et al. Traumatic aortic rupture: false-positive aortographic diagnosis due to atypical ductus diverticulum. AJR Am J Roentgenol. 1988,150(4):793-6. doi: 10.2214/ajr.150.4.793. [PubMed: 3258092].

8. Yu T, Zhu X, Tang L, Wang D, Saad N. Review of CT angiography of aorta. Radiol Clin North Am. 2007;45(3):461-83. doi: 10.1016/j.rcl.2007.04.010. [PubMed: 17601503] viii. 